\title{
Final height and body mass index in adult survivors of childhood acute lymphoblastic leukemia treated without cranial radiotherapy: a retrospective longitudinal multicenter Italian study
}

Patrizia Bruzzi ${ }^{1}$, Barbara Predieri ${ }^{1}$, Andrea Corrias ${ }^{2}$, Alberto Marsciani ${ }^{3}$, Maria Elisabeth Street ${ }^{4}$, Aurora Rossidivita ${ }^{5}$, Paolo Paolucci ${ }^{1}$ and Lorenzo lughetti ${ }^{*}$

\begin{abstract}
Background: Young adult survivors of childhood acute lymphoblastic leukemia (ALL) treated with protocols including cranial radiotherapy demonstrate a persistent weight gain and reduced final height. Published reports on the effects on growth of different oncologic therapies are conflicting and difficult to interpret because they combined children treated with both cranial irradiation and multi-agent chemotherapy. Our study investigated the effect of chemotherapy alone on body mass index (BMI) and on growth at the achievement of final height in a homogeneous cohort of Italian childhood ALL survivors.

Methods: We retrospectively studied 162 Caucasian patients treated on the Italian Association of Pediatric Hematology and Oncology protocols without radiotherapy between 1989 and 2000 at five Italian centers with 107 inclusions (58 males). Height- and BMI-standard deviation score (SDS) were collected at diagnosis of ALL, at the end of treatment and at the achievement of final height. Changes in height SDS and BMI SDS with time were analyzed using dependent sample Student's t-test.

Results: A significant reduction of height-SDS was documented during treatment in both genders. This reduction of height-SDS was not followed by an appropriate catch-up growth, despite the achievement of a mean final height within the normal range. At diagnosis females showed a lower mean BMI-SDS than males. During treatment, in the whole population, BMI-SDS increased significantly. After it, while males lost BMI-SDS, females showed its persistent increase.

Conclusions: Survivors of childhood ALL generally seemed to achieve a normal final height with a BMI within the normal range. These parameters appeared to be only minimally affected by chemotherapy. Nevertheless, height catch-up growth was not completed after chemotherapy in both genders and all patients experienced an increase of BMI-SDS during chemotherapy that only females seemed to conserve until the achievement of final height.
\end{abstract}

\footnotetext{
* Correspondence: iughetti.lorenzo@unimore.it

${ }^{1}$ Pediatric Unit, Department of Medical and Surgical Sciences for Mothers,

Children and Adults, University of Modena \& Reggio Emilia, Via del Pozzo, 71,

41124 Modena, Italy

Full list of author information is available at the end of the article
} 


\section{Background}

Acute lymphoblastic leukemia (ALL) is the most common malignancy in children and represents $80 \%$ of all leukemia cases [1]. Recent progress in risk-adapted treatment for childhood ALL has secured eight-year event-free survival rates of approximately 90\% [2-4]. Consequently, the late side-effects of the cancer treatment have obtained an increased attention and the long-term monitoring of survivors has become an important part of their overall health care [5]. Treatment of ALL during childhood is associated with final height deficit. Young age at diagnosis and radiotherapy are considered the major risk factors [6]. Moreover, adult survivors of childhood ALL have a fourfold excess risk of mortality from cardiovascular disease. Obesity seems highly prevalent among female and survivors treated with radiotherapy [7].

Nowadays, ALL survivors form the largest group of long-term survivors from childhood cancer, even if they are a heterogeneous group considering therapeutic protocols. In last decades, in most of them, cranial radiotherapy has been replaced by intrathecal chemotherapy, as standard central nervous system prophylaxis and treatment, and a reduced percentage of children have received cranial radiation [8] with a consequent reduction of sequelae related to this treatment modality. However, it has been suggested that also chemotherapy can negatively affect growth and endocrine functions $[9,10]$. Published reports on the effects on growth of these therapies are conflicting and difficult to interpret because most studies have analyzed growth in children treated with both cranial irradiation and combination chemotherapy and disentangling the adverse contribution of these two major therapeutic modalities has proved tricky [11-13].

To evaluate the impact on growth, we performed a retrospective multicenter study in a large pediatric ALL population treated without radiotherapy, followed until the achievement of final height.

\section{Methods}

\section{Design and setting}

This study was a longitudinal, retrospective and multicenter study: we reviewed the clinical notes of patients treated for ALL at five Italian pediatric oncologic centers (Modena, Turin, Rome, Rimini and Parma) on Italian Association of Pediatric Hematology and Oncology (AIEOP) protocols, without radiotherapy, from 1989 to 2000, and followed until the achievement of adult height. Inclusion criteria comprised the successful completion of the treatment (standard risk protocols) and a continued first remission. Exclusion criteria included: relapse, exposure to radiotherapy and/or bone marrow transplant, the presence of other diseases potentially influencing growth (i.e. Down's syndrome, neurofibromatosis type 1) and of chronic treatment with any other medication apart from the AIEOP protocols which might affect growth (i.e. growth hormone therapy, sex steroid) and lack of complete auxological data. Details concerning ALL treatment protocols were published elsewhere [14] and summarized in Table 1.

Provincial Ethical Committee approved the protocol study (practice 185/11).

\section{Data collection}

Age, height and weight at diagnosis of ALL (sT), at the end of treatment (EoT), and at final height (FH) were extracted from the record of each eligible patient. Uniformly, in every center, height was measured to the nearest $0.1-\mathrm{cm}$ with a wall-mounted stadiometer (Harpenden, Crymych; UK); body weight was measured to the nearest $0.1-\mathrm{kg}$ and body mass index (BMI) was obtained from the weight in $\mathrm{kg} /$ height in meters squared and expressed as standard deviation-score (SD-S) with respect to chronological age. The auxological instruments were routinely checked and calibrated. Height- and BMI- SDS were calculated for each value using age- and sex- specific World Health Organization (WHO) growth chart 2007 [15]. Parental height was also collected to estimate target height $(\mathrm{TH})$, calculated according to the formula: $[$ (mother's height +13$)+$ father's height $] / 2$ in males and $[$ (mother's height - 13) + father's height $] / 2$ in females [16]. Final height $(\mathrm{FH})$ was defined as the standing height achieved when the linear growth velocity during the preceding year was less than $1 \mathrm{~cm} /$ year.

For each participant, demographic and therapeutic information was obtained, including gender, ethnicity, diagnostic white cell count (WBC) at sT and treatment modalities.

\section{Data analysis}

All results, apart from ages expressed by median, were reported as the mean $\pm \mathrm{SD}$. Parametric statistical analysis (STATISTICA $^{\text {tw }}$ software, StatSoft Inc., Tulsa, OK, USA) was performed using dependent sample Student's t-test to detect mean changes in height SDS and BMI SDS from diagnosis of ALL to final height.

Data were also analyzed according to gender and to groups of age (younger or older than four years at diagnosis). Independent $\mathrm{t}$-test was performed to detect differences between groups. Gender, WBC, age at diagnosis, height at diagnosis and BMI at diagnosis, genetic target height were analyzed in a univariate regression model with final height SDS as dependent variable through Pearson's correlation. Potential predictors of final height SDS and BMI SDS at FH were analyzed by multivariate regression models.

A P value below 0.05 was considered statistically significant. 
Table 1 Characteristics of treatment protocols

\begin{tabular}{|c|c|c|c|c|c|c|c|c|c|}
\hline Protocols & 87 & 8801 & 8802 & 8805 & 9101 & 9102 & $9501-9502$ armA & 9502 armB & 2000 \\
\hline PDN & 2500 & 1830 & 1830 & 150 & 2030 & 1970 & 1970 & 1620 & 1910 \\
\hline VCR & 20.5 & 9 & 12 & 9 & 12 & 12 & 12 & 15 & 18 \\
\hline DNM & 180 & 160 & 160 & - & 120 & 120 & - & 120 & 120 \\
\hline MTX IT & V & v & v & $\checkmark$ & v & v & v & v & v \\
\hline L-ASP & 5400 & 80000 & 80000 & - & 80000 & 80000 & 120000 & 120000 & 80000 \\
\hline 6-MP & 6000 & 29920 & 25900 & - & 5100 & 28920 & 27350 & 6710 & 6830 \\
\hline MTX IV & 180 & 1540 & 1500 & 30 & 1488 & 1500 & 1488 & 1500 & 1500 \\
\hline CPM & - & 2000 & 3000 & 1600 & 1000 & 3000 & 1000 & 3000 & 2500 \\
\hline DESA & - & 189 & 249 & 300 & 249 & 249 & 261 & 297 & 409 \\
\hline $6-\mathrm{TG}$ & - & 900 & 900 & - & 840 & 840 & 780 & 780 & 780 \\
\hline ARA-C & - & 600 & 600 & 900 & 600 & 1800 & 600 & 1600 & $600-1800$ \\
\hline IFO & - & - & - & 12000 & - & - & - & - & - \\
\hline VM-26 & - & - & - & 600 & - & - & - & - & - \\
\hline ADM & - & 60 & 120 & 150 & 120 & 120 & 120 & 120 & $60-120$ \\
\hline Num. patients exposed & 2 & 1 & 2 & 4 & 5 & 28 & 2 & 57 & 6 \\
\hline
\end{tabular}

Legend: Drugs are expressed as cumulative dose (mg/mq). PDN, prednisolone; VCR, vincristine; DNM, daunorubicin; MTX, metotrexate; IT, intrathecal; $\vee$ included; L-ASP; L-asparaginase (UI/mq); 6-MP, 6-mercatopurine; IV, intravenously; CPM, cyclophosphamide; DESA, dexamethasone; 6-TG, 6-thioguanine; ARA-C, cytosine arabinoside.; IFO, ifosfamide; VM-26,teniposide; ADM, adriamycin.

\section{Results}

Of 162 Caucasian patients treated on AIEOP ALL87, 88, 91, 95 and 2000 protocols without radiotherapy from 1989 to 2000, 107 met inclusion criteria. Causes of exclusion enclosed: relapse (7.4\% of initial population), exposure to radiotherapy $(6.7 \%)$ and lack of data (19.7\%). None was excluded because of the presence of other diseases or of other chronic treatment potentially influencing growth. Only auxological parameters at sT were available in the 32 non-participants patients excluded because of lacking data. No statistical differences were detected between included and excluded patients among available variables (Table 2).

Table 2 Meadian age (years; range); Height-SDS (media \pm SDS); Height-SDS adjusted according to target height (media \pm SDS) and BMI-SDS (media \pm SDS) in study population and non-participants and according to gender from sT to FH

\begin{tabular}{|c|c|c|c|c|c|}
\hline & $\begin{array}{l}\text { Total participant } \\
\text { population }\end{array}$ & $\begin{array}{l}\text { Participants males } \\
\text { (58 pts) }\end{array}$ & $\begin{array}{l}\text { Participant females } \\
\text { (49 pts) }\end{array}$ & $\begin{array}{c}\text { Non-participans males } \\
\text { (17 pts) }\end{array}$ & $\begin{array}{c}\text { Non-participans females } \\
\text { (15 pts) }\end{array}$ \\
\hline \multicolumn{6}{|c|}{ Meadian age } \\
\hline sT & $5.57(1.20-13.73)$ & $5.93(1.31-12.85)$ & $5.15(1.20-13.73)$ & $5.84(1.15-12.74)$ & $5.12(1.14-13.45)$ \\
\hline EoT & $7.60(3.0-15.98)$ & $7.97(3.23-14.97)$ & $7.16(3.0-15.98)$ & / & / \\
\hline $\mathrm{FH}$ & $17.52(14.05-23.98)$ & $17.68(14.05-23.98)$ & $17 \cdot 24(14.05-23.7)$ & / & / \\
\hline \multicolumn{6}{|c|}{ Height-SDS } \\
\hline sT & $0.61 \pm 1.04$ & $0.62 \pm 1.05$ & $0.60 \pm 1.05$ & $0.60 \pm 1.02$ & $0.62 \pm 1.09$ \\
\hline EoT & $0.25 \pm 1.08(0.000)$ & $0.30 \pm 1.09(0.003)$ & $0.19 \pm 1.09(0.000)$ & / & / \\
\hline $\mathrm{FH}$ & $0.18 \pm 1.13(0.000)$ & $0.27 \pm 1.03(0.013)$ & $0.07 \pm 1.25(0.000)$ & / & / \\
\hline \multicolumn{6}{|c|}{ Height-SDS adjusted TH } \\
\hline sT & $0.45 \pm 1.22$ & $0.51 \pm 1.38$ & $0.38 \pm 1.22$ & / & / \\
\hline EoT & $0.04 \pm 1.2(0.000)$ & $0.18 \pm 1.36(0.043)$ & $-0.12 \pm 1.11(0.000)$ & / & / \\
\hline FH & $0.15 \pm 1.20(0.000)$ & $0.37 \pm 1.23$ & $-0.13 \pm 1.11(0.022)$ & / & / \\
\hline \multicolumn{6}{|c|}{ BMI-SDS } \\
\hline sT & $0.15 \pm 1.32$ & $0.39 \pm 1.30$ & $-0.12 \pm 1.31 \dagger$ & $0.35 \pm 1.24$ & $-0.09 \pm 1.20$ \\
\hline EoT & $0.58 \pm 1.34(0.000)$ & $0.82 \pm 1.29(0.010)$ & $0.29 \pm 1.36(0.015) \dagger$ & / & / \\
\hline FH & $0.51 \pm 1.03(0.010)$ & $0.49 \pm 1.09$ & $0.54 \pm 0.96(0.001)$ & / & / \\
\hline
\end{tabular}

Only significant $p$-values versus sT are expressed into brackets. + Significant $p$-values Males versus Females (BMI-SDS sT: males vs females: $p$ 0.0427; EoT: males vs females: $p$ 0.0431). 
Demographic data of participants and non-participants are shown in Table 2.

Among participants, there was no significant difference between male and female groups in age. The median time from diagnosis to assessment of $\mathrm{FH}$ was $11.90 \pm 3.26$ years (range 4.23 -18.46).

Table 2 lists anthropometric data over time.

At every step-time, both males and females had a mean height- and BMI-SDS within the normal range (Figures 1 and 2). At sT, children appeared generally wellnourished, showing a mean SDS of +0.61 for height and +0.15 for BMI. Only one girl presented a height-SDS less than -2 SD, but appropriate for her TH SDS (corresponding to $-2.70 \mathrm{SD}$ ). Analyzing BMI SDS distribution at sT, 7 children were thin (BMI SDS less than -2 SD) and the same number were obese (BMI SDS more than $+2 \mathrm{SD})$.

\section{Changes with time in height-SDS}

In the whole population, a significant reduction of height-SDS was documented during treatment (from sT to EoT) in both genders (Table 2). This reduction of height-SDS was not followed by an appropriate catch-up growth (Figure 1). In fact, after the end of chemotherapy, height-SDS further decreased both in females and in males.

TH-SDS was $0.02 \pm 1.10$ SDS in the whole group, $-0.08 \pm$ 0.79 SDS in males and $0.16 \pm 1.40$ in females. At sT, height-SDS adjusted according to $\mathrm{TH}$ was higher than at EoT and at FH (Table 2). The discrepancy in height-SDS from TH-SDS reduced over time (TH SDS - sT SDS vs TH SDS - FH SDS: -0.59 vs. -0.16 ; -0.70 vs. -0.35 ; -0.44 vs. -0.09 in the whole population, males and females; respectively). Only females achieved a FH SDS significantly reduced than data at sT (Table 2).

In the whole population FH-SDS correlated with height-SDS at sT (Figure 3A) and TH-SDS (Figure 3B).

\section{Changes with time in BMI-SDS}

As far as BMI-SDS is concerned, at diagnosis females showed a lower mean BMI-SDS than males (Table 2). During follow-up, in the whole population, BMI-SDS increased significantly both during treatment and after it until the achievement of FH. After the end of chemotherapy the variation in BMI SDS significantly differed between males and females (BMI SDS FH - BMI SDS EoT: $-0.32 \pm 1.23$ vs. $0.24 \pm 1.34$ SDS, respectively, p 0 . 023): males decreased significantly their BMI-SDS (FH vs. EoT: p 0.047), whereas females demonstrated no improvement in BMI SDS (FH vs. EoT: $\mathrm{p}$ 0.210) (Figure 2). Therefore, at FH only females showed a significant increase of BMI-SDS than at sT (Table 2).

\section{Age of exposure to chemotherapy}

According to age, 47 children were younger than four years at diagnosis of ALL (median age 3.06; range 1.20 3.89 years). Other 60 presented at sT a median age of 7.79 years (range 4.15 - 13.73 years). There was no significant difference between groups in sex distribution. During chemotherapy, a significant reduction of height-SDS was registered in both groups and it still persisted at $\mathrm{FH}$ (Table 3). BMI-SDS increased significantly from sT to EoT in both group, but it was still increased in comparison to the previous at sT only among children exposed to chemotherapy at a younger age (Table 3 ).

\section{Multiple regression analysis}

Multiple regression analysis identified $\mathrm{TH}$ and height SDS at sT as independent predictive factors for FH (coeff. 0.04, SE 0.02; coeff. 0.46, SE 0.12, respectively). Height SDS together with BMI SDS at ST was also identified as independent predictive factors for final BMI SDS (coeff. 0.30, SE 0.11; coeff. 0.41, SE 0.12, respectively).
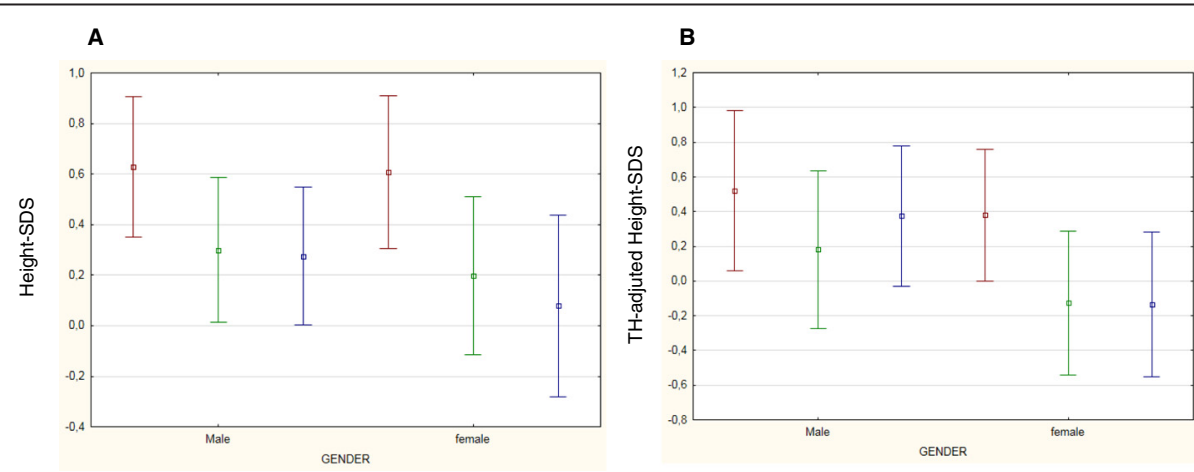

Figure 1 Mean Height-SDS (A) and mean height-SDS adjusted according to TH (B) changes with time in both gender. Legend: Data at diagnosis of ALL (ST) are colored in red. Data at the end of treatment (EOT) are colored in green. Data at final height (FH) are colored in blue. 


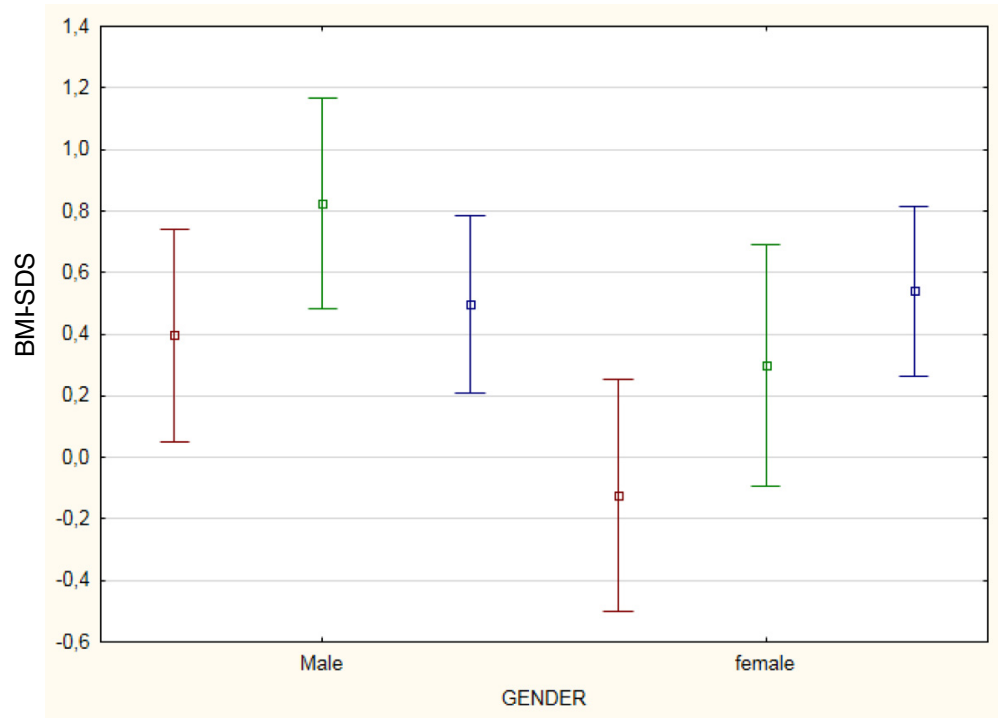

Figure 2 Mean BMI-SDS changes with time in both gender. Legend: Data at diagnosis of ALL (ST) are colored in red. Data at the end of treatment (EOT) are colored in green. Data at final height (FH) are colored in blue.

\section{Discussion}

According to our knowledge, this is the first study examining long-term growth outcomes in a wide cohort of un-irradiated Italian survivors from childhood ALL.

\section{Changes with time in height-SDS}

Growth impairment has already been reported as a frequent complication of the treatment of ALL [17]. Patients treated when younger than four years and who received cranial irradiation seem to be the more affected $[18,19]$. Nevertheless, a variety of other factors can contribute to growth impairment, including decreased nutritional intake, psychosocial dysfunction, chemotherapy and steroid therapy [20]. Data on long-term growth in children treated with chemotherapy alone are scarce and discordant $[9,12,13,18,21-26]$.
Our data demonstrate that chemotherapy minimally affected final height, confirming some short-term previous published findings $[18,24,25,27]$. In 2013, Vandecruys and colleagues described the longitudinal growth of 67 adult survivors of childhood ALL, treated from 1983 to 1989 according to European Organization for Research and Treatment of Cancer 58831/2 protocols with chemotherapy as the only treatment modality, and demonstrated a decrease in FH SDS from the time of diagnosis of -0.53 SDS in the standard-risk ALL group (45 patients) and of -0.73 SDS in the medium- or high-risk survivors (22 patients) [26]. In our study, survivors showed at FH a significant mean height loss of - 0.42 SDS (p 0 .000) compared to height SDS at diagnosis and, analyzing height-SDS adjusted according to $\mathrm{TH}$, the loss in SDS from sT to FH still persisted (-0.30; p 0.000). Differences could be due to the inclusion in our study of a
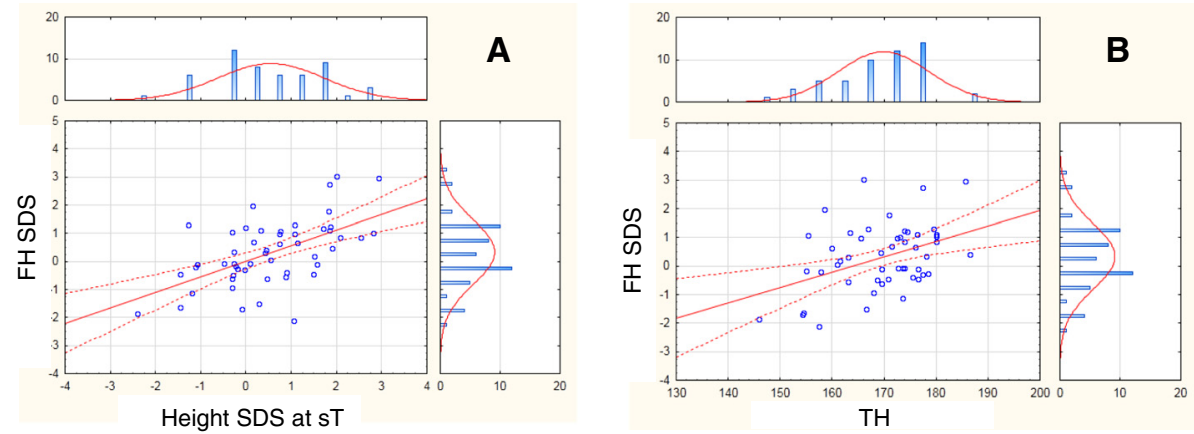

Figure 3 Significant correlations between FH and height SDS at diagnosis (A) $(r=0.571, p=0.018)$ and between FH and TH (B) $(r=0.410, p=0.000)$ in the whole population. 


\begin{tabular}{|c|c|c|}
\hline & $<4$ years & $\geq 4$ years \\
\hline \multicolumn{3}{|c|}{ Height SDS } \\
\hline sT & $0.54 \pm 1.06$ & $0.67 \pm 1.03$ \\
\hline Еот & $0.14 \pm 1.13(0.000)$ & $0.34 \pm 1.05(0.003)$ \\
\hline $\mathrm{FH}$ & $0.08 \pm 1.13(0.001)$ & $0.26 \pm 1.14(0.004)$ \\
\hline \multicolumn{3}{|c|}{ BMI SDS } \\
\hline sT & $-0.03 \pm 1.20$ & $0.30 \pm 1.40$ \\
\hline ЕoT & $0.48 \pm 1.42(0.005)$ & $0.65 \pm 1.29(0.023)$ \\
\hline $\mathrm{FH}$ & $0.49 \pm 0.97(0.005)$ & $0.53 \pm 1.08$ \\
\hline
\end{tabular}

Only significant $\mathrm{p}$-values versus sT are expressed into brackets.

larger number of survivors treated on more recent chemotherapy protocols. The damage induced by chemotherapy could impede a complete catch-up growth, even if our survivors reached a FH within the normality. In fact, only $\mathrm{TH}$ and height-SDS at sT directly correlated with FH and they were both identified as independent predictive factors for $\mathrm{FH}$ in the multiple regression analysis, demonstrating than genetic potentiality together with growth pattern before ALL still remain the two main factors influencing FH.

In irradiated population, girls typically experienced greater growth impairment than boys [11,28]. Also in our study, analyzing data adjusted according to $\mathrm{TH}$, only females showed a significant persistent reduction of height-SDS data, while males seemed to partially catch up after the end of chemotherapy. Because of the retrospective design of our study and the lack of a description of pubertal data, we could only hypothesized that it is possibly due to the early occurrence of puberty in female survivors of childhood ALL but not in males, as already described in literature $[29,30]$.

How chemotherapy can affect growth is still unclear, even because hypothalamic-pituitary cells together with liver and chondrocyte do not have a high multiplicative capacity and, therefore, they have not usually been considered vulnerable to the action of chemotherapeutic agents. A reduction of growth hormone $(\mathrm{GH})$ secretion induced by chemotherapy could be supposed. Rose and colleagues documented a hypothalamic-pituitary abnormality after chemotherapy in $83 \%$ of 18 hematological malignancy survivors (17 ALL) who were referred to their Clinic because of slow growth [31]. GH deficiency developed in 9 survivors. Even if this report did not represent a study of prevalence, authors hypothesized that chemotherapy alone may affect hypothalamic neurons through the loss of hypothalamic releasing or inhibitory hormone functions or through an altered processing of pituitary hormone. Host factors which might be associated with greater susceptibility to chemotherapy could be considered contributing factors [31]. On the contrary, Vandecruys and colleagues evaluated GH status in their population through glucagon stimulation test at the end of chemotherapy. In the $28 \%$ of cases, they demonstrated a decrease of GH secretion. This biochemical status did not correlate with the reduction in height SDS from diagnosis or end of treatment to FH [26]. Moreover, patients with an altered peak GH level at the end of chemotherapy were retested at the onset of puberty and demonstrated a normalized response to the GH stimulation test [26]. In older studies, a condition of $\mathrm{GH}-$ deficiency requiring GH replacement therapy has reported prevalence of 0.9 and $1.2 \%$ of childhood survivors of ALL treated with chemotherapy alone [32,33]. In our study, data were collected retrospectively and we did not investigate GH secretion in our population. Nevertheless, the demonstration of limited growth during chemotherapy could support the hypothesis that GH secretion could be directly and acutely altered by chemotherapeutic agents and that, in acute phases, both ALL and its treatment can caused severe catabolic effects in children, leading to increasing protein breakdown and reducing protein synthesis. The growth-promoting and metabolic actions of $\mathrm{GH}$ are mediated by specific $\mathrm{GH}$ receptors. The absence of or reduction in functional proteins might result in a condition of partial, transient and reversible GH insensitivity [34]. All our patients were exposed to high dose, intravenous MTX associated to its intrathecal administrations and to glucocorticoids in pre-induction, induction and re-induction phases (Table 1). Mild late effects on growth could be due to a direct, structural negative effect of chemotherapy on epiphysis with partial recovery [35]. Up to now, we can demonstrate a significant and not obvious role of chemotherapy in long-term growth impairment, but we can only hypothesize a synergic effect of all chemotherapeutic compounds in altering the multitude and the functionality of cells in growth plate.

\section{Changes with time in BMI-SDS}

Obesity is probably the most worrisome and common late effect in survivors of childhood ALL [36]. Razzouk in 2007 documented that $33.7 \%$ of 101 young adults treated previously with chemotherapy-alone for ALL were obese [37]. In addition, children treated for childhood cancer may be at unusually high risk from the consequences of obesity, particularly cardiovascular and metabolic comorbidities. Our data help in clarifying changes in BMI SDS over time, meanwhile and after chemotherapy for ALL. Excess weight gain usually starts soon after diagnosis, particularly during the first year of therapy, and it seems to be maintained $[20,38]$. Nevertheless, up to now, long-term BMI data in an unirradiated population are not yet fully described and short-term data are extrapolated from small populations [39]. The rate of weight gain varies between studies [10,37,40-42]. In our study, BMI-SDS increased 
significantly from the start of treatment and the increase persisted until the achievement of FH. Increased energy intake and reduced habitual physical activity are commonly considered the main responsible factors of weight gain. During treatment, patients usually undergo changes in their lifestyle. The loss of physical activity may start during hospitalization or unwellness period of the patient, but it persists into adulthood due to a number of factors, including diminished exercise capacity, impaired motor function, diminished interest in recreational activity and over-protectiveness of the child's primary caregivers [36]. In adulthood, almost $44 \%$ of ALL survivors are unlikely to meet the Centers for Disease Control and Prevention Recommendations for physical activity and over $74 \%$ are less likely to be physically active [43] and their dietary intake is not concordant with specific dietary recommendation [44]. In our study, BMI SDS at sT is identified as independent predictive factor for BMI-SDS at FH. This might indirectly document that, independently from the diagnosis of ALL and its treatment, environmental factors as a negative lifestyle acquired in the family setting during first years of life may intervene in the development of obesity during and after the treatment of ALL.

Exposure to chemotherapeutic medications seemed to differ between genders: females seemed more sensitive to effects of chemotherapy and they might be more at risk to present greater and more persistent metabolic alterations than males. Up to now, none of therapeutic choices and/or doses could explain this sexual dimorphism. Others factors should be considered. Female survivors are already known to be less active and to have a more unbalanced caloric intake than males [45]. Nevertheless, a definitive explanation of gender dymorphism could be identified only when other risk factors responsible for an indirect damage of the hypothalamuspituitary region or of the metabolic pathways will be studied [36]. Our findings confirm and reinforce recent Harper's data $[27,46]$. The group from Cambridge presented data from only 27 ALL survivors (17 females) who reached FH. Only in females, persisting increases in weight-SDS and BMI-SDS (+1.45 vs. +0.46, p $<0.0001)$ were evident at $\mathrm{FH}$ [27].

In our cohort, age at diagnosis did not correlate with final BMI SDS and it was not identified as its independent predictive factors. Nevertheless, examining population according to age-subgroups (younger and older than 4 years at sT), only younger children presented a persistent increase of BMI SDS after the end of chemotherapy. This might support that chemotherapy acts similarly to radiotherapy in altering body composition later-in-life via blunting hypothalamic leptin sensitivity and via modification of metabolism.

\section{Conclusions}

In conclusion, our study demonstrates that chemotherapy alone, as in AIEOP protocols, minimizes the loss in $\mathrm{FH}$ SDS together with the increase in BMI SDS in adult survivors of childhood. These results could be positively influenced by the fact that, in all the included Italian centers, the management of oncologic patients involves pediatric endocrinologists from the early stages of treatment, allowing early evaluation of pathological conditions and, consequently, early interventions. Nevertheless, both males and females experienced a loss in height-SDS during chemotherapy that was not followed by an appropriate catch-up growth, and an increase of BMI-SDS. Physicians have to keep in mind that cancer survivors, because of treatment (potential cardiotoxic chemotherapy), are prone to develop cardiovascular disease. Obesity can increase the risk for morbidity and mortality due to diabetes, coronary artery disease, atherosclerosis and other diseases related to overweight in adulthood [38], especially in females [47]. Our findings confirmed females as more at risk of either becoming or persisting obese long after chemotherapy. This enables us to focus our efforts in preventing their weight gain and long-term complications of obesity. Nevertheless, the majority of adult survivors are followed by primary health care physicians, rather than by an oncologic center. This leads to an imperative need: educate all health workers on preventing these risks and on developing specific intervention strategies, including correct dietary and lifestyle choices [48] in ALL survivors, even if treated with chemotherapy only.

\section{Abbreviations}

ADM: Adriamycin; AIEOP: Italian Association of Pediatric Hematology and Oncology; ALL: Acute Lymphoblastic Leukemia; ARA-C: Cytosine arabinoside; BMI: Body Mass Index; CPM: Cyclophosphamide; DESA: Dexamethasone; DNM: Daunorubicin; EOT: End of Treatment; FH: Final Height; GH: Growth Hormone; IFO: Ifosfamide; IT: Intrathecal; IV: Intravenously; L-ASP: Lasparaginase; MTX: Methotrexate; PDN: prednisolone; SD: Deviation Score; SDS: Standard Deviation Score; ST: diagnosis of ALL; TH: Target Height; VCR: Vincristine; VM-26: teniposide; WBC: White Blood Cells; 6-MP: 6mercatopurine; 6-TG: 6-thioguanine.

\section{Competing interests}

The authors declare that they have no competing interests.

\section{Authors' contributions}

PB, AC, AM, MES and AR collected data. PB and LI conceived the study and its design, coordinated it and wrote the manuscript. BP performed the statistical analysis. PP supervised the project as the head of department and reviewed the manuscript making important intellectual contributions. All authors read and approved the final manuscript.

\section{Author details}

${ }^{1}$ Pediatric Unit, Department of Medical and Surgical Sciences for Mothers, Children and Adults, University of Modena \& Reggio Emilia, Via del Pozzo, 71, 41124 Modena, Italy. ${ }^{2}$ Regina Margherita Children's Hospital, Department of Pediatric Endocrinology and Diabetology, University of Torino, Piazza Polonia, 94, 10126 Torino, Italy. ${ }^{3}$ Pediatric Department, Infermi Hospital, viale Luigi Settembrini, 2, 47900 Rimini, Italy. ${ }^{4}$ Department of Pediatrics, University Hospital of Parma, via Gramsci, 14, 43126 Parma, Italy. ${ }^{5}$ Pediatric Department, Cattolica University, Largo Agostino Gemelli, 8, Roma, Italy. 
Received: 1 February 2014 Accepted: 10 September 2014

Published: 22 September 2014

\section{References}

1. Redaelli A, Laskin BL, Stephens JM, Botteman MF, Pashos CL: A systematic literature review of the clinical and epidemiological burden of acute lymphoblastic leukemia (ALL). Eur J Cancer Care 2005, 14(1):53-62.

2. Pui CH, Robison LL, Look AT: Acute lymphoblastic leukaemia. Lancet 2008, 371:1030-1043

3. Smith MA, Altekruse SF, Adamson PC, Reaman GH, Seibel NL: Declining childhood and adolescent cancer mortality. Cancer 2014, 120(16):2497-2506.

4. Gatta G, Rossi S, Foschi R, Trama A, Marcos-Gragera R, Pastore G, Peris-Bonet R, Stiller C, Capocaccia R, EUROCARE Working Group: Survival and cure trends for European children, adolescents and young adults diagnosed with acute lymphoblastic leukemia from 1982 to 2002. Haematologica 2013, 98(5):744-752.

5. Essig S, Li Q, Chen Y, Hitzler J, Leisenring W, Greenberg M, Sklar C, Hudson MM, Armstrong GT, Krull KR, Neglia JP, Oeffinger KC, Robison LL, Kuehni CE, Yasui Y, Nathan PC: Risk of late effects of treatment in children newly diagnosed with standard-risk acute lymphoblastic leukaemia: a report from the Childhood Cancer Survivor Study cohort. Lancet Oncol 2014, 15(8):841-851.

6. Vilela MI, Serravite Mde O, Oliveira NB, de Brito PC, Ribeiro-Oliveira A Jr, Viana MB: Height deficit and impairment of the GH/IGF-1 axis in patients treated for acute lymphoblastic leukemia during childhood. Horm Res Paediatr 2013, 79(1):9-16.

7. Nottage KA, Ness KK, Li C, Srivastava D, Robison LL, Hudson MM: Metabolic syndrome and cardiovascular risk among long-term survivors of acute lymphoblastic leukaemia - From the St. Jude Lifetime Cohort. BrJ Haematol 2014, 165(3):364-374.

8. Smith MA, Seibel NL, Altekruse SF, Ries LAG, Melbert DL, O'Leary M, Smith FO, Reaman GH: Outcomes for children and adolescents with cancer: challenges for the twenty-first century. J Clin Oncol 2010, 28:2625-2634.

9. Chow EJ, Friedman DL, Yasui Y, Whitton JA, Stovall M, Robinson LL, Sklar CA: Decreased adult height in survivors of childhood acute lymphoblastic leukemia: a report from the Childhood Cancer Survivor Study. J Pediatr 2007, 150:370-375.

10. Breene RAL, Williams RM, Hartle J, Gattens M, Acerini CL, Murray M!: Auxological changes in UK survivors of childhood acute lymphoblastic leukemia treated without cranial irradiation. BJC 2011, 104:746-749.

11. Cicognani A, Cacciari E, Rosito P: Longitudinal growth and final height in long-term survivors of childhood leukemia. Eur J Pediatr 1994, 153:726-730.

12. Birkebaek NH, Clausen N: Height and weight pattern up to 20 years after treatment for acute lymphoblastic leukaemia. Arch Dis Child 1998, 79:161-164

13. Hokken-Koelega AC, van Doorn JW, Hahlen K, Stijnen T, de Muinck Keizer-Schrama SM, Drop SL: Long-term effects of treatment for acute lymphoblastic leukemia with and without cranial irradiation on growth and puberty: a comparative study. Pediatr Res 1993, 33:577-582.

14. Conter V, Aricò M, Basso G, Biondi A, Barisone E, Messina C, Parasole R, De Rossi G, Locatelli F, Pession A, Santoro N, Micalizzi C, Citterio M, Rizzari C, Silvestri D, Rondelli R, Lo Nigro L, Ziino O, Testi AM, Masera G, Valsecchi MG: Long-term results of the Italian Association of Pediatric Hematology and Oncology (AIEOP) Studies 82, 87, 88, 91, and 95 for childhood acute lymphoblastic leukemia. Leukemia 2010, 24(2):255-264.

15. World Health Organization Growth Reference 2007. [www.who.int/ growthref]

16. Tanner JM, Goldstein $H$, Whitehouse RH: Standards for children's height at ages 2-9 years allowing for height of parents. Arch Dis Child 1970, 47:755-762.

17. Schriock EA, Schell MJ, Carter M, Hustu O, Ichs JJ: Abnormal growth patterns and adult short stature in 115 long-term survivors of childhood leukemia. J Clin Oncol 1991, 9:400-405.

18. Vilela MI, Viana MB: Longitudinal growth and risk factors for growth deficiency in children treated for acute lymphoblastic leukaemia. Pediatr Blood Cancer 2007, 48(1):86-92.

19. Ben Arush MW, Elhasid I: Effects of radiotherapy on the growth of children with leukemia. Pediatr Endocrinol Rev 2008, 5:785-788.
20. Withycombe JS, Post-white JE, Meza JL, Hawks RG, Smith LM, Sacks N, Seibel $\mathrm{NL}$ : Weight patterns in children with higher risk acute lymphoblastic leukemia: a report from the children's oncology group for CCG 1961. Pediatr Blood Cancer 2009, 53:1249-1254.

21. Katz JA, Pollock BH, Jacaruso D, Morad A: Final attained height in patients successfully treated for childhood acute lymphoblastic leukemia. J Pediatr 1993, 123:546-552.

22. Holm K, Nysom K, Hertz $\mathrm{H}$, Muller J: Normal final height after treatment for acute lymphoblastic leukemia without irradiation. Acta Paediatr 1994 83:1287-1290.

23. Dalton VK, Rue M, Silverman LB, Gelber RD, Asselin BL, Barr RD, Clavell LA, Hurwitz CA, Moghrabi A, Samson Y, Schorin M, Tarbell NJ, Sallan SE, Cohen LE: Height and weight in children treated for acute lymphoblastic leukemia: relationship to CNS treatment. J Clin Oncol 2003, 21:2953-2960.

24. Sklar C, Mertens A, Walter A, Mitchell D, Nesbit M, O'Leary M, Hutchinson R, Meadows $A$, Robison L: Final height after treatment for childhood acute lymphoblastic leukemia: comparison of no cranial irradiation with 1800 and 2400 centigrays of cranial irradiation. J Pediatr 1993, 123(1):59-64.

25. Bongers ME, Francken AB, Rouwé C, Kamps WA, Postma A: Reduction of adult height in childhood acute lymphoblastic leukemia survivors after prophylactic cranial irradiation. Pediatr Blood Cancer 2005, 45(2):139-143.

26. Vandecruys E, Dhooge C, Craen M, Benoit Y, De Schepper J: Longitudinal linear growth and final height is impaired in childhhod acute lymphoblastic leukemia survivors after treatment without cranial irradiation. J Pediatr 2013, 163(1):268-273.

27. Harper RLC, Breene RAL, Gattens M, Williams RM, Murray MJ: Non-irradiated females survivors of childhood acute lymphoblastic leukemia are at risk of long-term increases in weight and body mass index. $\mathrm{Br} J$ Haematol 2013, 163(4):510-513.

28. Uruena M, Stanhope R, Chessells JM, Leiper AD: Impaired pubertal growth in acute lymphoblastic leukemia. Arch Dis Child 1991, 66:1403-1407.

29. Leiper AD, Stanhope R, Kitching P, Chessells JM: Precocious and premature puberty associated with treatment of acute lymphoblastic leukemia. Arch Dis Child 1987, 62(11):1107-1112.

30. Didcock E, Davies HA, Didi M, Ogilvy Stuart AL, Wales JK, Shalet SM: Pubertal growth in young adults survivors of childhood leukemia. J Clin Oncol 1995, 13(10):2503-2507.

31. Rose SR, Schreiber RE, Kearney NS, Lustig RH, Danish RK, Burghen GA, Hudson MM: Hypothalamic dysfunction after chemotherapy. J Pediatr Endocrinol Metab 2004, 17(1):55-66.

32. Haddy TB, Mosher RB, Nunez SB, Reaman GH: Growth hormone deficiency after chemotherapy for acute lymphoblastic leukemia in children who have not received cranial radiation. Pediatr Blood Cancer 2006, 46(2):258-261.

33. Leung W, Rose SR, Zhou Y, Hancock ML, Burstein S, Schriock EA, Lustig R, Danish RK, Evans WE, Hudson MM, Pui CH: Outcomes of growth hormone replacement therapy in survivors of childhood acute lymphoblastic leukemia. J Clin Oncol 2002, 20(13):2959-2964.

34. Arguelles B, Barrios V, Buno M, Madero L, Argente J: Anthropometric parameters and their relationship to serum growth hormone-binding protein and leptin levels in children with acute lymphoblastic leukemia: a prospective study. Eur J Endocrinol 2000, 143(2):243-250.

35. van Leeuwen BL, Hartel RM, Jansen HW, Kamps WA, Hoekstra HJ: The effect of chemotherapy on the morphology of the growth plate and metaphysis of the growing skeleton. Eur J Surg Oncol 2003, 29(1):49-58.

36. Iughetti L, Bruzzi P, Predieri B, Paolucci P: Obesity in patients with acute lymphoblastic leukemia in childhood. Ital I Pediatr 2012, 38:4.

37. Razzouk I, Rose SR, Hongeng S, Wallace D, Smeltzer MP, Zacher M, Pui CH, Hudson MM: Obesity in survivors of childhood acute lymphoblastic leukemia and lymphoma. J Clin Oncol 2007, 25:1183-1189.

38. Chow EJ, Pihoker C, Hunt K, Wilkinson K, Friedman DL: Obesity and hypertension among children after treatment for acute lymphoblastic leukaemia. Cancer 2007, 110:2313-2320.

39. Craig F, Leiper AD, Stanhope R, Brain C, Meller ST, Nussey SS: Sexually dimorphic and radiation dose dependent effect of cranial irradiation on body mass index. Arch Dis Child 1999, 81:500-504.

40. Garmey EG, Liu Q, Sklar CA, Meacham LR, Mertens AC, Stovall MA, Yasui Y, Robison LL, Oeffinger KC: Longitudinal changes in obesity and body mass index among adult survivors of childhood acute lymphoblastic leukemia: a report from the Childhood Cancer Survivor Study. J Clin Oncol 2008, 26(28):4639-4645. 
41. Oeffinger K, Mertens A, Sklar C, Yasui Y, Fears T, Stovall M, Vik TA, Inskip PD, Robison LL: Obesity in adult survivors of childhood acute lymphoblastic leukemia: a report from the childhood cancer survivor study. J Clin Oncol 2003, 21:1359-1365.

42. Didi M, Didcock E, Davies HA, Ogilvy-Stuart AL, Wales JK, Shalet SM: High incidence of obesity in young adults after treatment of acute lymphoblastic leukemia in childhood. J Pediatr 1995, 127:63-67.

43. Florin TA, Fryer GE, Miyoshi T, Weitzman M, Mertens AC, Hudson MM, Sklar CA, Emmons K, Hinkle A, Whitton J, Stovall M, Robison LL, Oeffinger KC: Physical inactivity in adult survivors of childhood acute lymphoblastic leukemia: a report from the childhood cancer survivor study. Cancer Epidemiol Biomarkers Prev 2007, 16:1356-1363.

44. Robien K, Ness KK, Klesges LM, Baker KS, Gurney JG: Poor adherence to dietary guidelines among adult survivors of childhood acute lymphoblastic leukemia. J Pediatr Hematol Oncol 2008, 30(11):815-822.

45. Jarvela LS, Niinikoski H, Lahteenmaki PM, Heinonen OJ, Kapanen J, Arola M, Kemppainen J: Physical activity and fitness in adolescent and young adult long-term survivors of childhood acute lymphoblastic leukemia. J Cancer Surviv 2010, 4(4):339-345.

46. Mayer El, Reuter M, Dopfer RE, Ranke MB: Energy expenditure, energy intake and prevalence of obesity after therapy for acute lymphoblastic leukemia during childhood. Horm Res 2000, 53:193-199.

47. Armstrong GT, Oeffinger KC, Chen Y, Kawashima T, Yasui Y, Leisenring W, Stovall M, Chow EJ, Sklar CA, Mulrooney DA, Mertens AC, Border W, Durand JB, Robison LL, Meacham LR: Modifiable risk factors and major cardiac events among adult survivors of childhood cancer. J Clin Oncol 2013, 31(29):3673-3680.

48. World Cancer Research Fund. American Institute for Cancer Research. [www.dietandcancerreport.org - http://www.health.gov/DietaryGuidelines/]

doi:10.1186/1471-2431-14-236

Cite this article as: Bruzzi et al:: Final height and body mass index in adult survivors of childhood acute lymphoblastic leukemia treated without cranial radiotherapy: a retrospective longitudinal multicenter Italian study. BMC Pediatrics 2014 14:236.

\section{Submit your next manuscript to BioMed Central and take full advantage of:}

- Convenient online submission

- Thorough peer review

- No space constraints or color figure charges

- Immediate publication on acceptance

- Inclusion in PubMed, CAS, Scopus and Google Scholar

- Research which is freely available for redistribution 